\title{
Zinc deficiency during in vitro maturation of porcine oocytes causes meiotic block and developmental failure
}

\author{
YUBYEOL JEON $^{1}$, JUNCHUL DAVID YOON ${ }^{1}$, LIAN CAI $^{1}$, SEON-UNG HWANG $^{1}$, \\ EUNHYE KIM ${ }^{1}$, ZHONG ZHENG ${ }^{1}$, EUIBAE JEUNG ${ }^{2}$, EUNSONG LEE ${ }^{3}$ and SANG-HWAN HYUN ${ }^{1}$ \\ ${ }^{1}$ Laboratory of Veterinary Embryology and Biotechnology (VETEMBIO); \\ ${ }^{2}$ Laboratory of Veterinary Biochemistry and Molecular Biology, College of Veterinary Medicine, \\ Chungbuk National University, Cheongju, Chungbuk 361-763; ${ }^{3}$ Laboratory of Theriogenology, College of Veterinary Medicine, \\ Kangwon National University, Chuncheon, Gangwon 200-710, Republic of Korea
}

Received September 30, 2014; Accepted June 23, 2015

DOI: $10.3892 / \mathrm{mmr} .2015 .4125$

\begin{abstract}
The present study investigated the effects of zinc deficiency during in vitro maturation (IVM) of porcine oocytes. Zinc deficiency was induced by administering the membrane-permeable zinc chelator $\mathrm{N}, \mathrm{N}, \mathrm{N}^{\prime}, \mathrm{N}^{\prime}$-tetrakis-(2-pyridylmethyl)-ethylendiamine (TPEN). First, theeffects ofzinc deficiency duringIVMonaTPEN-treated group and a TPEN+zinc-treated group compared with a control group were assessed. The oocyte maturation rates and subsequent embryonic developmental competence of the TPEN+zinc-treated oocytes were similar to those of the control oocytes (metaphase II [MII] rate, 93.0 and $92.7 \%$, respectively, and blastocyst [BL] formation rate, 42.0 and $40.0 \%$, respectively). These results were significantly different from those obtained for the TPEN-treated oocytes (MII rate, 0.61\%; BL formation rate, $0 \%$ ). Although the TPEN-treated oocytes were arrested at metaphase I (MI), the distribution of microtubules was normal. However, microfilament formation was abnormal in the TPEN-treated oocytes. Furthermore, the effect of a temporary zinc deficiency during IVM on oocyte maturation and subsequent embryonic development was assessed. TPEN $(10 \mu \mathrm{M})$ was added to the IVM medium for $0,7,15$ or $22 \mathrm{~h}$. The 0 h-treated oocytes showed an $83.9 \%$ MII rate, while the 7 h-treated oocytes had a significantly lower MII rate (44.8\%). Most of the 15- and $22 \mathrm{~h}$-treated oocytes were arrested at MI (MI rate: 98.0 and $97.2 \%$, respectively; MII rate, $0 \%$ in both groups). Reductions in the BL formation were dependent on the TPEN treatment duration $(29.3,9.2,0$, and $0 \%$ after 0,7 , 15 and $22 \mathrm{~h}$, respectively). In conclusion, zinc is an essential element for successful oocyte maturation and embryonic
\end{abstract}

Correspondence to: Professor Sang-Hwan Hyun, Laboratory of Veterinary Embryology and Biotechnology, (VETEMBIO), College of Veterinary Medicine, Chungbuk National University, 52 Naesudong-ro, Seowon-gu, Cheongju, Chungbuk 361-763, Republic of Korea E-mail: shhyun@cbu.ac.kr

Key words: in vitro maturation, oocytes, porcine, zinc, TPEN development in pigs. Zinc deficiency caused a meiotic block and had lasting effects on early embryonic development.

\section{Introduction}

In vitro production (IVP), including in vitro maturation (IVM) and somatic cell nuclear transfer, is an important technology for producing transgenic cloned pigs. Oocyte quality influences early embryonic development, fetal growth, pregnancy and the health of the offspring (1). Thus, a better understanding and improved IVM are required to generate transgenic cloned pigs efficiently.

To date, there has been extensive research regarding the optimal conditions for IVM. Addition of various hormones and growth factors, including luteinizing hormone, follicle-stimulating hormone (2), transforming growth factor, androstenedione (3), pregnant mare serum gonadotropin, human chorionic gonadotropin (hCG) $(4,5)$, insulin-like growth factor I (6), and estradiol-17 $\beta(5,7)$, to IVM media exerts positive effects during meiosis (8). Cumulus cells also have an important role in oocyte maturation. Cumulus cells regulate the resumption of meiosis and protect oocytes from oxidative stress (9). Reactive oxygen species (ROS) cause oxidative damage to oocytes due to an improper in vitro environment $(10,11)$, while glutathione $(\mathrm{GSH})$ reduces ROS and oxidative stress (12). Various factors can increase GSH, including cysteine (13), cysteamine, glutamine (14), vascular endothelial growth factor (15) and granulocyte-macrophage colony-stimulating factor (16). However, the in vitro oocyte quality remains inferior to the in vivo oocyte quality for transgenic pig production (17). Numerous aspects of oocyte maturation have remained to be determined; for example, porcine follicular fluid $(\mathrm{pFF})$ contains various unknown factors, including growth factors, cytokines and trance minerals. These factors can influence oocyte maturation and subsequent embryonal development. However, the factors or mechanisms have yet to be determined.

The mammalian body contains small amounts of trace minerals, which are necessary to maintain life and health (18). These minerals are involved in the formation of bones and teeth, acid-base balance, fluid and moisture equilibrium, and are 
used as components of neurotransmitters and hormones (18). Trace minerals influence embryonic and fetal survival, as well as other aspects of reproductive performance and growth in mammals (19). Of these, zinc is an important factor during reproduction and development.

Zinc is required for normal fetal growth and development (20). Zinc deficiency causes fetal teratogenesis, prolonged gestation, difficult labor, low birth weight and weak offspring $(21,22)$. In addition, zinc levels are increased 1.7- to 8.7-fold in porcine conceptuses compared to those in the endometrium or ovary between days 12 and 30 of gestation (23). This indicates that the developing conceptus requires increased uptake and/or utilization of zinc. Another potential pathway for zinc to influence pregnancy is by its effect on prostaglandin (PG)F2 $\alpha$ synthesis (24-27). Zinc is involved in the formation of PGs, as the arachidonic acid cascade is regulated by zinc enzymes. Zinc also has important roles in scavenging free oxygen radicals (28), DNA synthesis and gene transcription (29). Thus, zinc is thought to influence reproduction and development, and it exists in the oocyte cytoplasm and maturational environment during oocyte maturation; however, its role and influence during porcine IVM have not been sufficiently considered by previous studies. Only a previous study by our group investigated the effects of zinc supplementation during porcine IVM, showing that supplementation of $0.8 \mu \mathrm{g} / \mathrm{ml}$ zinc during IVM of porcine oocytes improved embryonic development prior to implantation (30).

The aim of the present study was to clarify the role of zinc during IVM. For this, zinc deficiency was induced using the membrane-permeable zinc chelator TPEN, and the effects on cumulus cell expansion, nuclear maturation, cytoskeletal organization, GSH and ROS levels, and subsequent embryonic development were evaluated.

\section{Materials and methods}

Chemicals. Unless otherwise indicated, all chemicals and reagents used in the present study were purchased from Sigma-Aldrich (St. Louis, MO, USA).

Oocyte collection and IVM. The current study was approved by the Committee on the Ethics of Animal Experiments (permit no. CBNUA-584-13-01; Chungbuk National University, Cheongju, Republic of Korea). Porcine ovaries were obtained from 496 Landrace x Duroc crossbreed gilts (sows) from a local slaughterhouse (Dong-A, Chengju, Korea) and transported to the laboratory within $2 \mathrm{~h}$ in $0.9 \%(\mathrm{w} / \mathrm{v})$ $\mathrm{NaCl}$ supplemented with penicillin-G (100 IU/ml) and streptomycin sulfate $(100 \mathrm{mg} / \mathrm{l})$ at $30-35^{\circ} \mathrm{C}$. Follicular fluid with oocytes was aspirated from antral follicles (3-6 mm) using an 18-gauge needle connected to a $10-\mathrm{ml}$ disposable syringe and collected into a $15-\mathrm{ml}$ centrifuge tube. Cumulus-oocyte complexes (COCs) were recovered under a stereomicroscope (SZ51; Olympus, Tokyo, Japan), and those with at least three layers of compact cumulus cells and a homogenous cytoplasm were selected for IVM. The selected COCs were washed three times in 4-(2-hydroxyethyl)-1-piperazineethanesulfonic acid-buffered Tyrode's medium containing $0.05 \%(\mathrm{w} / \mathrm{v})$ polyvinyl alcohol (TLH-PVA), and transferred to $500 \mu$ l tissue culture medium 199 (Invitrogen Life Technologies, Carlsbad,
CA, USA) supplemented with $0.6 \mathrm{mM}$ cysteine, $0.91 \mathrm{mM}$ sodium pyruvate, $10 \mathrm{ng} / \mathrm{ml}$ epidermal growth factor, $75 \mu \mathrm{g} / \mathrm{ml}$ kanamycin, $1 \mu \mathrm{g} / \mathrm{ml}$ insulin and $10 \%$ (v/v) pFF. pFF was aspirated from follicles $(3-7 \mathrm{~mm})$ obtained from pre-pubertal gilt ovaries. After centrifugation at $1,600 \mathrm{xg}$ for $30 \mathrm{~min}$, the supernatants were collected and filtered sequentially through 1.2- and 0.45- $\mu \mathrm{m}$ syringe filters (Gelman Sciences, Ann Arbor, MI, USA). The prepared $\mathrm{pFF}$ was then stored at $-20^{\circ} \mathrm{C}$ until use. For maturation, the selected COCs were washed three times in oocyte maturation medium containing hormone supplements, and 50-60 oocytes were transferred to each well of a four-well Nunc dish (Roskilde, Denmark) containing $500 \mu \mathrm{l}$ of culture medium and equilibrated for at least $2 \mathrm{~h}$ with $5 \%$ $\mathrm{CO}_{2}$ at $39^{\circ} \mathrm{C}$ in a humidified atmosphere. During the first $22 \mathrm{~h}$, the COCs were matured with hormones $(10 \mathrm{IU} / \mathrm{ml}$ equine chorionic gonadotropin and $10 \mathrm{IU} / \mathrm{ml}$ hCG (Intervet, Boxmeer, the Netherlands). After $22 \mathrm{~h}$ of maturation with hormones, the COCs were washed twice and cultured in hormone-free IVM medium for an additional 18-20 h.

Assessment of nuclear maturation. After 40-42 h of culture, the oocytes were denuded by gently pipetting them in IVM medium containing $0.1 \%$ hyaluronidase followed by washing in TLH-PVA. The denuded oocytes were fixed for $5 \mathrm{~min}$ in fixative solution containing $2 \%$ formaldehyde and $0.25 \%$ glutaraldehyde and then stained in TLH-PVA containing $10 \mu \mathrm{g} / \mathrm{ml}$ Hoechst 33342 for $10 \mathrm{~min}$. The stained oocytes were examined by fluorescence microscopy (Nikon Corp., Tokyo, Japan) and classified according to their developmental stage as follows: Germinal vesicle, metaphase I (MI), anaphase I/telophase I or MII.

Experimental groups. Zinc deficiency was induced with TPEN. TPEN was prepared as a 1-mM stock solution and used at a final concentration of $10 \mu \mathrm{M}$. In experiment 1 , nuclear maturation, cytoskeletal component organization, GSH, ROS, and subsequent embryonic development in the following three groups were evaluated to investigate the effects of zinc deficiency during IVM: i) Treatment without TPEN (control); ii) treatment with $10 \mu \mathrm{M}$ TPEN for $22 \mathrm{~h}$ during IVM; and iii) treatment with $10 \mu \mathrm{M} \mathrm{TPEN}+10 \mu \mathrm{M}$ zinc (zinc sulfide) for $22 \mathrm{~h}$ during IVM. In experiment 2, the effects of the zinc deficiency period during IVM on oocyte maturation and subsequent embryonic development after PA were determined. TPEN $(10 \mu \mathrm{M})$ was added to the IVM medium for $0,7,15$ or $22 \mathrm{~h}$. After TPEN treatment, $10 \mu \mathrm{M}$ zinc was added to the IVM medium during the second half of IVM in all but the 0 -h group.

Immunofluorescence imaging. Oocytes were collected after IVM, fixed in $4 \%$ paraformaldehyde for $40 \mathrm{~min}$ and then permeabilized with $1 \%$ Triton X-100 for $30 \mathrm{~min}$. After incubation in am Image-iTTM FX Signal Enhancer (I36933; Invitrogen Life Technologies) for $30 \mathrm{~min}$, the oocytes were blocked with $1 \%$ bovine serum albumin (BSA; A9418; Sigma-Aldrich) in phosphate-buffered saline (PBS) for $1 \mathrm{~h}$ and then incubated with fluorescein isothiocyanate-conjugated monoclonal anti- $\alpha$-tubulin antibodies (F2168, 1:100; Sigma-Aldrich) or tetramethylrhodamine-conjugated phalloidin (P1951, 1:200; Sigma-Aldrich) for $1 \mathrm{~h}$ at $37^{\circ} \mathrm{C}$. After 

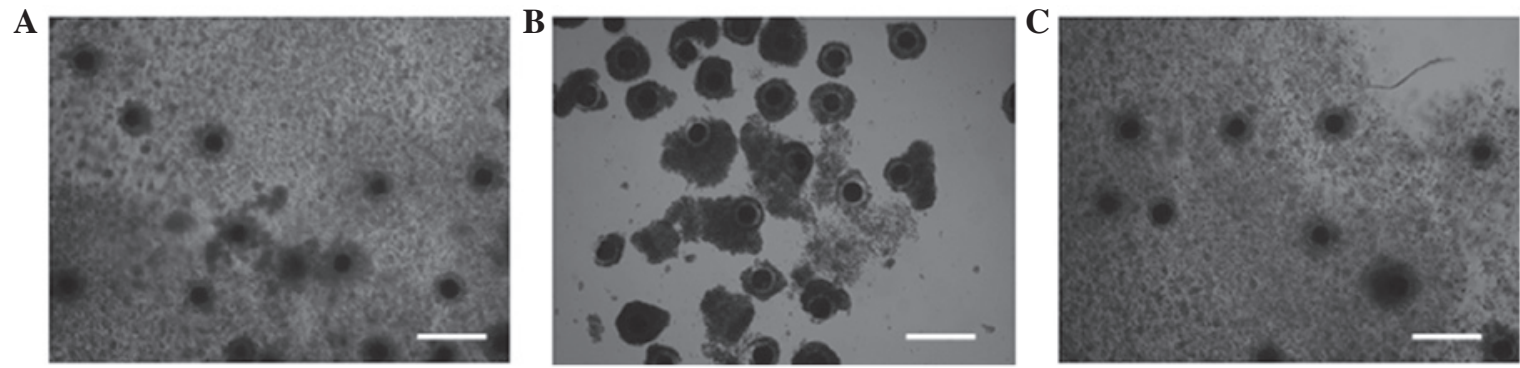

Figure 1. Effect of zinc deficiency during IVM on cumulus cell expansion at $42 \mathrm{~h}$ after IVM. (A) Control, (B) TPEN (10 $\mu \mathrm{M})$, (C) TPEN+zinc. Control and TPEN+zinc treatment groups showed abundant cumulus cell expansion. However, cumulus cell expansion was inhibited in the TPEN-treated group. Scale bar, $300 \mu \mathrm{m}$. IVM, in vitro maturation; TPEN, zinc chelator N,N,N',N'-tetrakis-(2-pyridylmethyl)-ethylendiamine.

nuclear staining with $10 \mu \mathrm{g} / \mathrm{ml}$ Hoechst 33342, The oocytes were mounted on slides with 1,4-diazabicyclo-(2.2.2) octane (P0126; Beyotime Institute of Biotechnology, Shanghai, China) and observed with a laser-scanning confocal microscope (TCS SP2 AOBS; Leica Microsystems, Wetzlar, Germany).

Measurement of intracellular ROS and GSH levels. The oocytes were sampled after $44 \mathrm{~h}$ of IVM to determine their intracellular ROS and GSH levels as described previously (31). Briefly, 2',7'-dichlorodihydrofluorescein diacetate (H2DCFDA; Invitrogen Life Technologies) and CellTracker Blue (4-chloromethyl-6.8-difluoro-7-hydroxycoumarin; Invitrogen Life Technologies) were used to detect intracellular ROS as green fluorescence and the GSH level as blue fluorescence. Ten oocytes from each treatment group were incubated in the dark for $30 \mathrm{~min}$ in TLH-PVA supplemented with $10 \mu \mathrm{M}$ H2DCFDA and $10 \mu \mathrm{M}$ CellTracker. After incubation, the oocytes were washed with Dulbecco's PBS (Invitrogen Life Techonologies) containing $0.1 \%$ (w/v) PVA and placed in $10-\mu \mathrm{l}$ microdrops, and fluorescence was detected under an epifluorescence microscope (TE300; Nikon) with ultraviolet filters (460 nm for ROS and $370 \mathrm{~nm}$ for GSH). Fluorescence images were saved as graphic files in TIFF format. The fluorescence intensities of the oocytes were analyzed with ImageJ software v. 1.41o (National Institutes of Health, Bethesda, MD, USA) and normalized to a control.

Parthenogenetic activation (PA). For PA, mature oocytes were activated with two pulses of $120 \mathrm{~V} / \mathrm{mm}$ of DC for $60 \mu \mathrm{sec}$ in $280 \mathrm{mM}$ mannitol containing $0.01 \mathrm{mM} \mathrm{CaCl}_{2}$ and $0.05 \mathrm{mM}$ $\mathrm{MgCl}_{2}$. Following electrical activation, the PA embryos were treated with $5 \mu \mathrm{g} / \mathrm{ml}$ cytochalasin B in IVC medium for $6 \mathrm{~h}$ at $39^{\circ} \mathrm{C}$ in a humidified atmosphere of $5 \% \mathrm{CO}_{2}$ in air.

In vitro embryo culture. The PA embryos were washed three times with IVC medium (porcine zygote medium 3) and cultured in 30- $\mu 1$ microdrops of IVC medium. Embryos in culture medium were covered with pre-warmed mineral oil and incubated at $39^{\circ} \mathrm{C}$ for 7 days under a humidified atmosphere of $5 \% \mathrm{O}_{2}, 5 \% \mathrm{CO}_{2}$ and $90 \% \mathrm{~N}_{2}$.

Embryo evaluation and total cell count. The day when PA was performed was designated as day 0 . The embryos were evaluated under a stereomicroscope for cleavage on day 2 (48 h). Blastocyst formation was assessed on day 7 (168 h).
To determine the total cell number in the blastocysts on day 7, blastocysts were collected and the zona pellucida of (if unhatched) was dissolved with $0.5 \%$ protease. The zona-free blastocysts were washed in PBS containing $1 \%$ (w/v) BSA and stained with $10 \mu \mathrm{g} / \mathrm{ml}$ Hoechst 33342 for $5 \mathrm{~min}$. Following a final wash in PBS-BSA, the blastocysts were fixed briefly (10 min) in 4\% paraformaldehyde in PBS. The blastocysts were mounted on glass slides in a drop of $100 \%$ glycerol, gently squashed under a cover slip and observed by fluorescence microscopy (Nikon) at x400 magnification.

Statistical analysis. Each experiment consisted of at least three replicates. All statistical analyses were performed using SPSS 17.0 software (SPSS Inc., Chicago, IL, USA). The GSH and ROS levels and embryonic development data (e.g., rate of cleavage, blastocyst formation and number of nuclei) were compared by a one-way analysis of variance, followed by Duncan's multiple range test. All values are expressed as the mean or mean \pm standard error of the mean. $\mathrm{P}<0.05$ was considered to indicate a statistically significant difference between values.

\section{Results}

Zinc deficiency inhibits oocyte maturation and subsequent embryo development. Cumulus cell expansion was observed after IVM. The control and TPEN+zinc treatment groups showed normal cumulus cell proliferation, while in the TPEN-treated group, cumulus cell proliferation did not proceed (Fig. 1).

Almost all oocytes in the TPEN-treated groups were arrested at MI. Only $0.61 \%$ of the oocytes matured to MII. By contrast, $>90 \%$ of the oocytes reached MII in the control and TPEN+zinc-treated groups (Table I).

Cytoskeletal organization was investigated by immunofluorescence staining to determine an accurate meiotic rate. Almost all oocytes in the control and TPEN+zinc-treated groups displayed a metaphase spindle and polar body (Fig. 2). By contrast, almost all of the TPEN-treated oocytes displayed only a metaphase spindle (Fig. 2). Although the meiotic stages were different, the shapes of the chromatin and spindle were normal in all groups. Only a few oocytes in the TPEN-treated group did not have a spindle signal.

In the control, a typical MII-stage distribution of microfilaments was observed. Strong signals were detected at the cortex (Fig. 3). The microfilament distribution was abnormal in the 
Table I. Effect of zinc deficiency during in vitro maturation on nuclear maturation of porcine oocytes.

\begin{tabular}{|c|c|c|c|c|c|}
\hline \multirow[b]{2}{*}{ Group } & \multirow[b]{2}{*}{$\begin{array}{l}\text { Oocytes cultured } \\
\text { for maturation }(\mathrm{n})^{\mathrm{a}}\end{array}$} & \multicolumn{4}{|c|}{ Number of oocytes (n) } \\
\hline & & $\begin{array}{l}\text { Germinal } \\
\text { vesicle }\end{array}$ & Metaphase I & $\begin{array}{c}\text { Anaphase and } \\
\text { telophase I }\end{array}$ & Metaphase II \\
\hline Control & 150 & 0 & $3.3 \pm 0.7^{b}$ & $4.0 \pm 1.2$ & $92.7 \pm 1.8^{\mathrm{b}}$ \\
\hline TPEN & 157 & $1.9 \pm 1.1$ & $96.2 \pm 1.0^{\mathrm{c}}$ & $1.3 \pm 0.6$ & $0.6 \pm 0.6^{c}$ \\
\hline $\mathrm{TPEN}+\mathrm{Zn}$ & 156 & 0 & $5.1 \pm 1.2^{\mathrm{b}}$ & $1.9 \pm 0.0$ & $93.0 \pm 1.2^{\mathrm{b}}$ \\
\hline
\end{tabular}

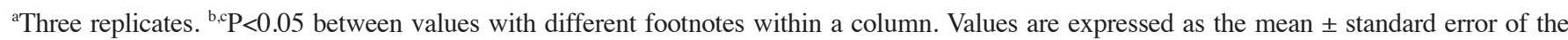
mean. TPEN, zinc chelator N,N,N',N'-tetrakis-(2-pyridylmethyl)-ethylendiamine.

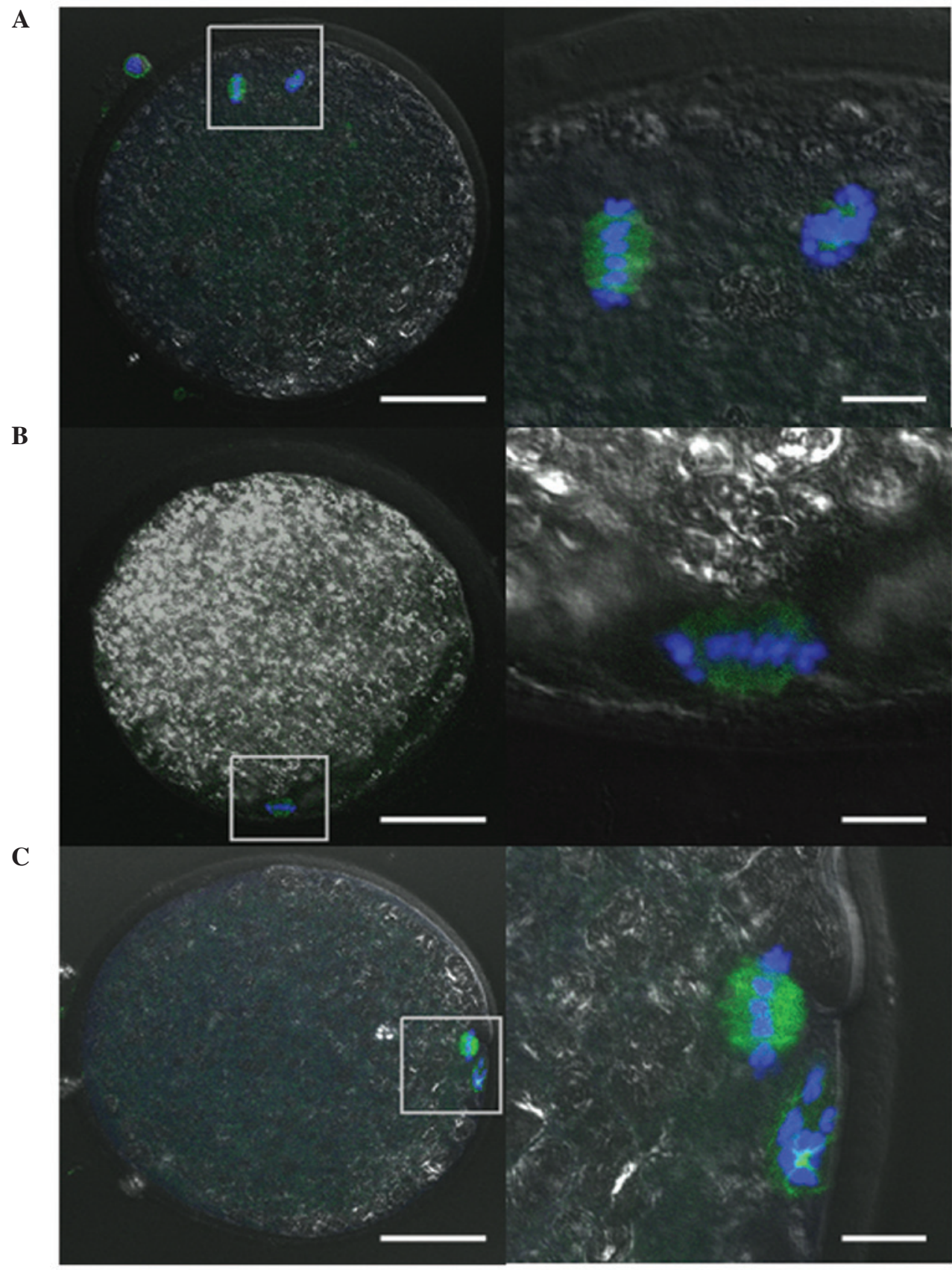

Figure 2. Immunofluorescence localization of microtubules in zinc-deficient porcine oocytes at $42 \mathrm{~h}$ after in vitro maturation. Microtubules were immunostained with anti- $\alpha$ tubulin (green) and DNA was counterstained with Hoechst (blue). (A) Oocytes of the control group showed metaphase plates and polar bodies at metaphase II stage. (B) TPEN-treated oocytes were arrested at metaphase I. (C) TPEN+zinc-treated oocytes showed metaphase plates and polar bodies at metaphase II stage. Scale bars, 50 and $10 \mu \mathrm{m}$ in left and right panels, respectively. TPEN, zinc chelator N,N,N',N'-tetrakis-(2-pyridylmethyl)-ethylendiamine. 
A

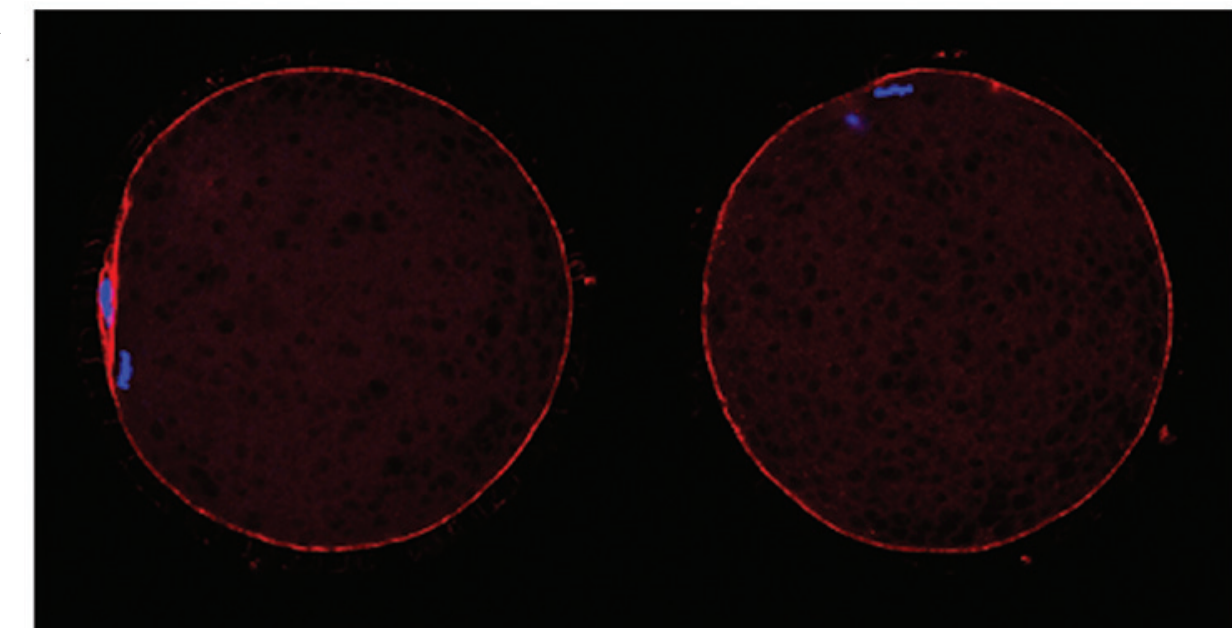

B

C

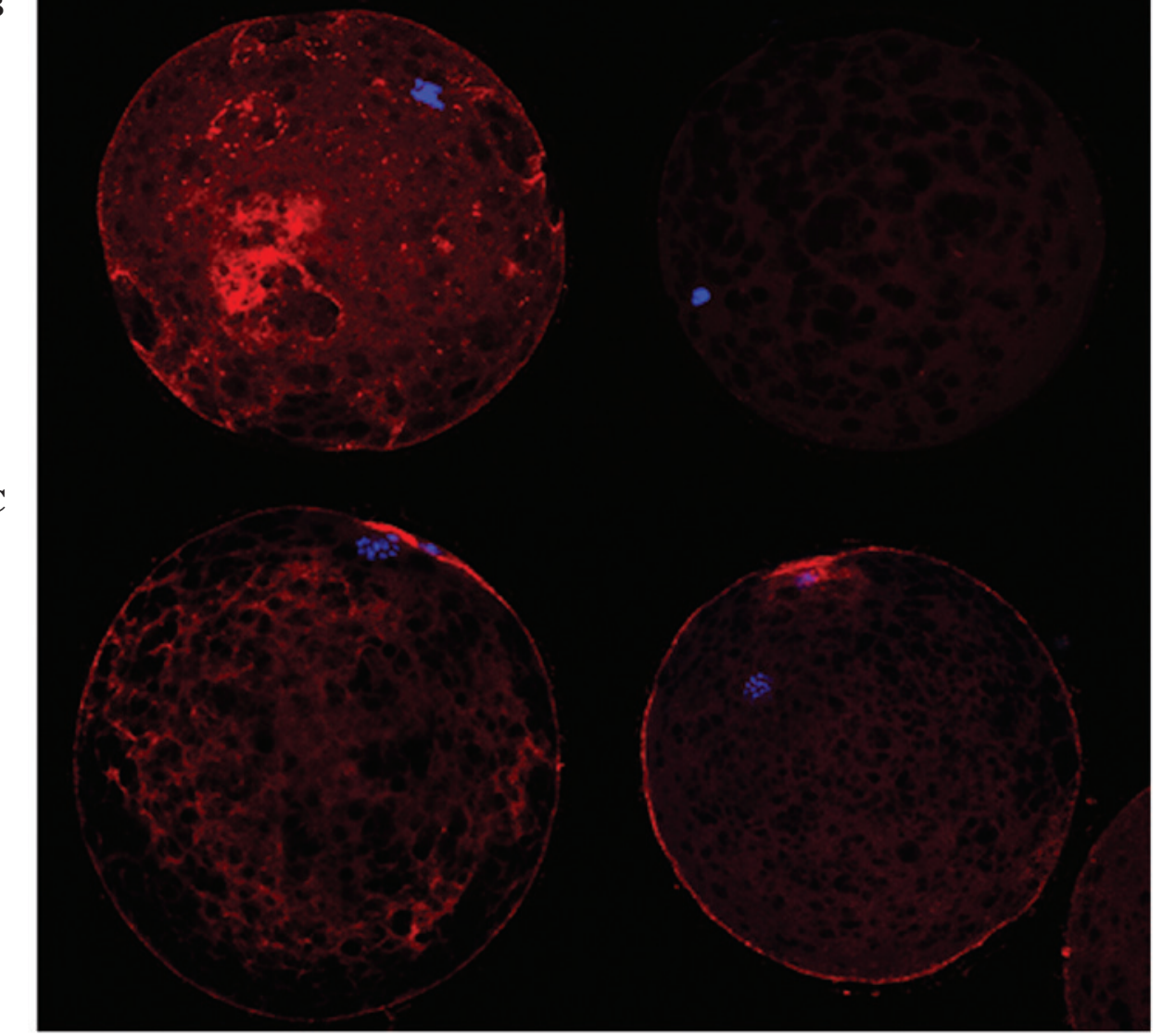

Figure 3. Immunofluorescence localization of microfilaments in zinc deficient porcine oocytes at $42 \mathrm{~h}$ after in vitro maturation. Microfilaments were immunostained with anti-microfilament (red) and DNA was counterstained with Hoechst (blue). (A) Oocytes of the control group were in metaphase II nuclear stage and showed normal microfilament distributions. (B) TPEN-treated oocytes were arrested at metaphase I and microfilaments were organized in abnormal patterns (left, irregular distribution of microfilament; right, microfilament signals were not present). (C) TPEN+zinc-treated oocytes were in metaphase II nuclear stage. Strong microfilament signals were detected in the cortex, while a number of week microfilament signals were present in cytoplasm. Scale bar, $50 \mu \mathrm{m}$. TPEN, zinc chelator $\mathrm{N}, \mathrm{N}, \mathrm{N}^{\prime}, \mathrm{N}^{\prime}$-tetrakis-(2-pyridylmethyl)-ethylendiamine.

TPEN-treated group; the microfilaments were irregularly distributed in the cytoplasm and cortex, which were unevenly shaped. Certain oocytes in the TPEN-treated group did not have a microfilament signal (Fig. 3). Most of the oocytes in the TPEN+zinc-treated group showed a relatively normal microfilament distribution. Weak microfilament signals were detected in the cytoplasm of certain oocytes.

The GSH and ROS levels were significantly altered in the TPEN-treated group; the GSH levels decreased significantly, while the ROS levels increased significantly (Fig. 4). The GSH and ROS levels changed slightly in the TPEN+zinc-treated group, but not significantly.

Subsequent development of PA embryos was also decreased in the TPEN-treated group. On day 2 of IVC, almost all oocytes in the TPEN-treated group were arrested at the one-cell stage (Fig. 5). Although the cleavage patterns on day 2 were slightly different between the control and TPEN+zinc-treated groups, the two groups showed normal cleavage patterns. A total of 40.0 and $42.0 \%$ of the embryos developed to blastocysts in the control and TPEN+zinc-treated groups, respectively 
Table II. Effect of zinc deficiency on embryonic development after parthenogenetic activation during in vitro maturation.

\begin{tabular}{|c|c|c|c|c|}
\hline \multirow[b]{2}{*}{ Group } & \multirow{2}{*}{$\begin{array}{c}\text { Embryos } \\
\text { cultured (n) }\end{array}$} & \multicolumn{2}{|c|}{ Embryos developed to } & \multirow[b]{2}{*}{ Total cell number in blastocyst } \\
\hline & & $\geq 2$-cell $(\%)$ & Blastocyst (\%) & \\
\hline Control & 157 & $72.9 \pm 2.8$ & $40.0 \pm 7.5$ & $51.0 \pm 6.2$ \\
\hline TPEN & 147 & 0 & 0 & - \\
\hline TPEN+Zn & 144 & $75.5 \pm 2.2$ & $42.0 \pm 6.7$ & $47.2 \pm 4.8$ \\
\hline
\end{tabular}

${ }^{a}$ Three replicates. Values are expressed as the mean \pm standard error of the mean. TPEN, zinc chelator N,N,N',N'-tetrakis-(2-pyridylmethyl)ethylendiamine.
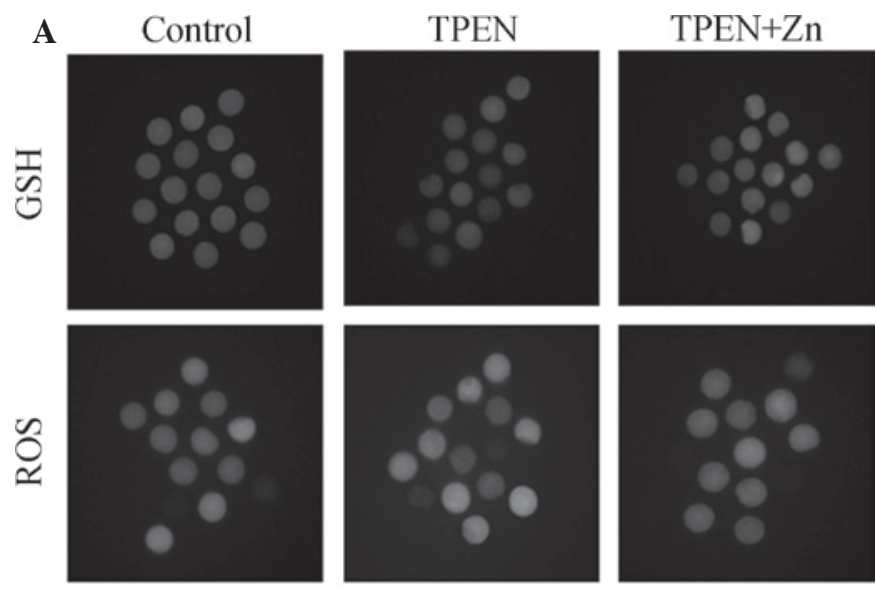

\section{B}

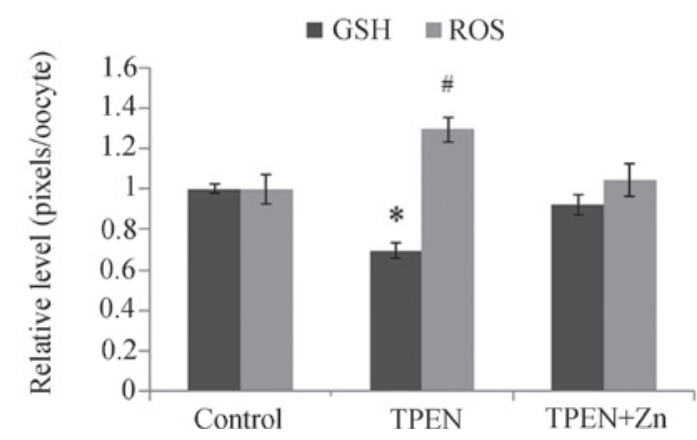

Figure 4. Epifluorescent photomicrographic images of in vitro matured porcine oocytes. (A) Oocytes were stained with (top row) CellTracker Blue and (bottom row) 2',7'-dichlorodihydrofluorescein diacetate to detect intracellular levels of GSH and reactive ROS, respectively. Metaphase-II oocytes derived from the control group, TPEN-treated group and TPEN+Zn-treated group. (B) Effect of zinc deficiency on intracellular GSH and ROS levels on porcine oocytes during in vitro maturation. Values are expressed as the mean \pm standard error of the mean $(n=3)$. ${ }^{*}, \mathrm{P}<0.05$ vs. control. ROS, reactive oxygen species; GSH, glutathione; TPEN, zinc chelator $\mathrm{N}, \mathrm{N}, \mathrm{N}^{\prime}, \mathrm{N}^{\prime}$-tetrakis-(2-pyridylmethyl)-ethylendiamine.

(Table II). No cleaved embryos or blastocysts were observed in the TPEN-treated group.

Zinc withdrawal inhibits oocyte maturation and subsequent embryonic development in a time-dependent manner. The cumulus cells in the group treated for $7 \mathrm{~h}$ were slightly expanded subsequent to IVM, whereas no expansion was observed in the groups treated for 15 and $22 \mathrm{~h}$ (Fig. 6).

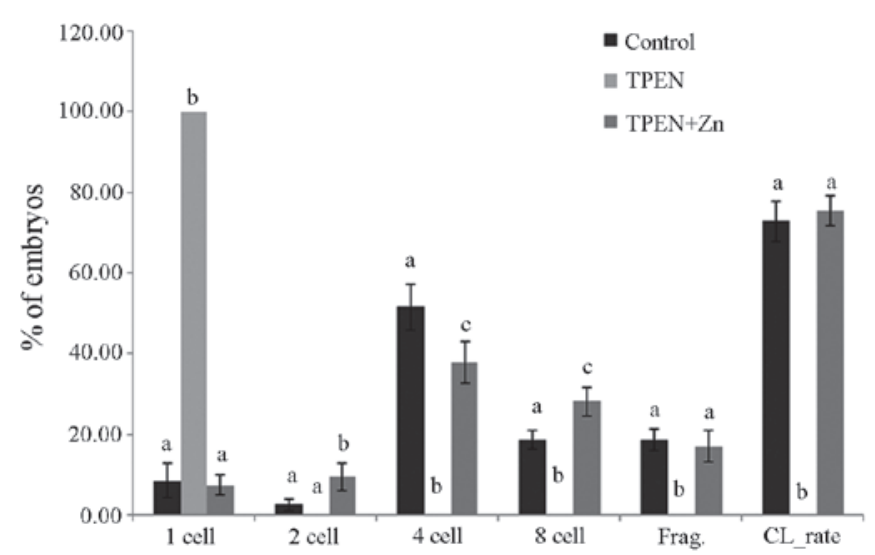

Figure 5. Effect of zinc deficiency in maturation medium on cleavage patterns on day 2. Values are expressed as the mean \pm standard error of the mean $(n=3)$. ${ }^{\mathrm{a}-\mathrm{c}} \mathrm{P}<0.05$ between values with different footnotes within a column. Frag, fragmented embryos, which contain unequally-sized blastomeres and multiple cellular fragments; CL_rate, cleave rates, ratio of 2- to 8-cell embryos; TPEN, zinc chelator N,N,N',N'-tetrakis-(2-pyridylmethyl)-ethylendiamine.

An assessment of nuclear maturation produced results that were similar to those for cumulus cell expansion. Nuclear maturation rates decreased with increasing TPEN treatment duration. The MI and MII rates in the control group were 11.5 and $83.9 \%$, respectively. The group treated for $7 \mathrm{~h}$ had MI and MII rates of 50.4 and $44.8 \%$, respectively. No MII oocytes were observed in the groups treated for 15 and $22 \mathrm{~h}$ (Table III). Approximately 98.0 and $97.2 \%$ of the oocytes in the groups treated for 15 and $22 \mathrm{~h}$, respectively, were in MI.

Subsequent development was also different with TPEN treatment time. The number of one-cell stage embryos on day 2 increased by increasing TPEN treatment duration. In the group treated for $7 \mathrm{~h}$, the rate of cleaved embryos decreased significantly compared to that in the control group. The numbers of two- and four-cell stage embryos decreased, while the numbers of one-cell stage and fragmented embryos increased. Most embryos did not cleave in the groups treated for 15 and $22 \mathrm{~h}$ (Fig. 7). The blastocyst formation rate and total cell number in the blastocysts were highest in the control group. The blastocyst formation rate and total cell number in the blastocysts in the group treated for $7 \mathrm{~h}$ decreased significantly (blastocyst formation rate, $10.4 \%$; total cell number, 23.2). Only 2.6 and $3.0 \%$ of the embryos developed beyond the two-cell stage in the groups treated for 15 and $22 \mathrm{~h}$, and no blastocysts formed (Table IV). 
Table III. Effect of zinc deficiency for various durations on nuclear maturation during in vitro maturation.

\begin{tabular}{|c|c|c|c|c|c|}
\hline \multirow[b]{2}{*}{$\begin{array}{l}\text { TPEN } \\
\text { treatment time }\end{array}$} & \multirow[b]{2}{*}{$\begin{array}{l}\text { Oocytes cultured } \\
\text { for maturation }(n)^{\text {a }}\end{array}$} & \multicolumn{4}{|c|}{ Oocytes at various stages $(\%)$} \\
\hline & & $\begin{array}{l}\text { Germinal } \\
\text { vesicle }\end{array}$ & Metaphase I & $\begin{array}{c}\text { Anaphase and } \\
\text { telophase I }\end{array}$ & Metaphase II \\
\hline $0 \mathrm{~h}$ & 105 & $0.9 \pm 0.9$ & $11.5 \pm 2.9^{\mathrm{b}}$ & $3.8 \pm 0.8^{\mathrm{d}}$ & $83.9 \pm 3.9^{\mathrm{d}}$ \\
\hline $7 \mathrm{~h}$ & 101 & $1.9 \pm 1.9$ & $50.4 \pm 1.3^{\mathrm{c}}$ & $3.0 \pm 0.1^{\mathrm{c}, \mathrm{d}}$ & $44.8 \pm 3.0^{\mathrm{c}}$ \\
\hline $15 \mathrm{~h}$ & 98 & $2.0 \pm 1.0$ & $98.0 \pm 1.0^{\mathrm{d}}$ & $0.0^{\mathrm{b}}$ & $0.0^{\mathrm{b}}$ \\
\hline $22 \mathrm{~h}$ & 103 & $1.9 \pm 0.9$ & $97.2 \pm 1.7^{\mathrm{d}}$ & $1.0 \pm 1.0^{\mathrm{b}, \mathrm{c}}$ & $0.0^{\mathrm{b}}$ \\
\hline
\end{tabular}

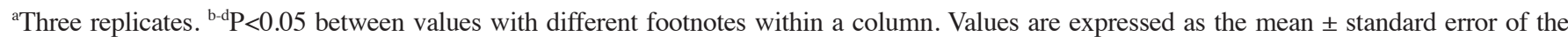
mean. TPEN, zinc chelator $\mathrm{N}, \mathrm{N}, \mathrm{N}^{\prime}, \mathrm{N}^{\prime}$-tetrakis-(2-pyridylmethyl)-ethylendiamine.

Table IV. Effect of zinc deficiency for various durations on embryonic development after parthenogenetic activation during in vitro maturation.

\begin{tabular}{|c|c|c|c|c|}
\hline \multirow{2}{*}{$\begin{array}{l}\text { TPEN } \\
\text { Treatment time }\end{array}$} & \multirow{2}{*}{$\begin{array}{l}\text { Embryos } \\
\text { cultured (n) }\end{array}$} & \multicolumn{2}{|c|}{ Embryos developed to } & \multirow[b]{2}{*}{ Cell number in blastocys } \\
\hline & & $\geq 2$-cell $(\%)$ & Blastocyst (\%) & \\
\hline $0 \mathrm{~h}$ & 101 & $65.3 \pm 1.4^{\mathrm{b}}$ & $29.7 \pm 1.2^{\mathrm{b}}$ & $51.4 \pm 4.5^{\mathrm{c}}$ \\
\hline $7 \mathrm{~h}$ & 107 & $42.6 \pm 4.8^{c}$ & $10.4 \pm 1.4^{\mathrm{c}}$ & $23.2 \pm 1.6^{\mathrm{d}}$ \\
\hline $15 \mathrm{~h}$ & 114 & $2.6 \pm 0.1^{\mathrm{d}}$ & $0.0^{\mathrm{d}}$ & - \\
\hline $22 \mathrm{~h}$ & 103 & $3.0 \pm 1.6^{\mathrm{d}}$ & $0.0^{\mathrm{d}}$ & - \\
\hline
\end{tabular}

${ }^{a}$ Three times replicates. ${ }^{b-d} \mathrm{P}<0.05$ between values with different footnotes within a column. Values are expressed as the mean \pm standard error of the mean. TPEN, zinc chelator $\mathrm{N}, \mathrm{N}, \mathrm{N}^{\prime}, \mathrm{N}^{\prime}$-tetrakis-(2-pyridylmethyl)-ethylendiamine.

A

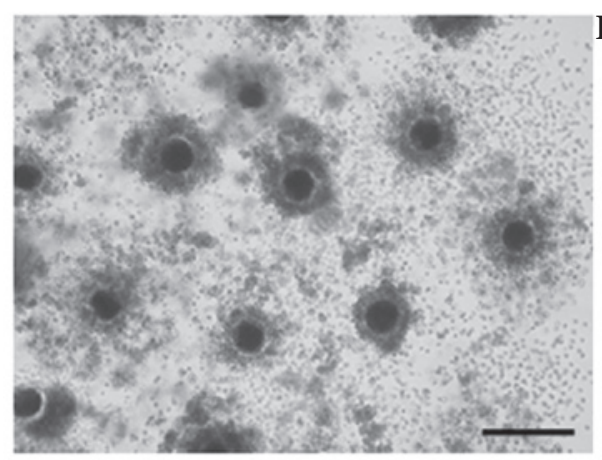

B

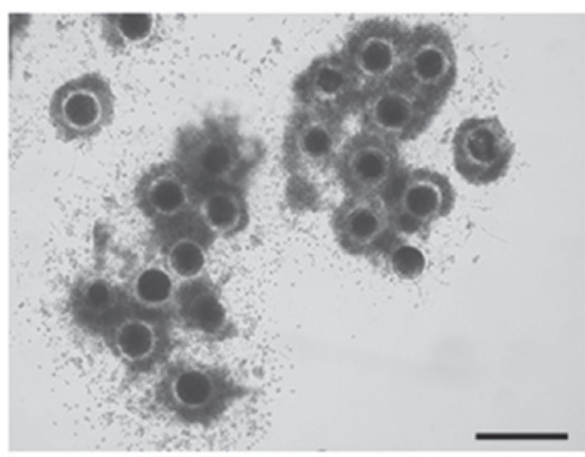

$\mathbf{C}$

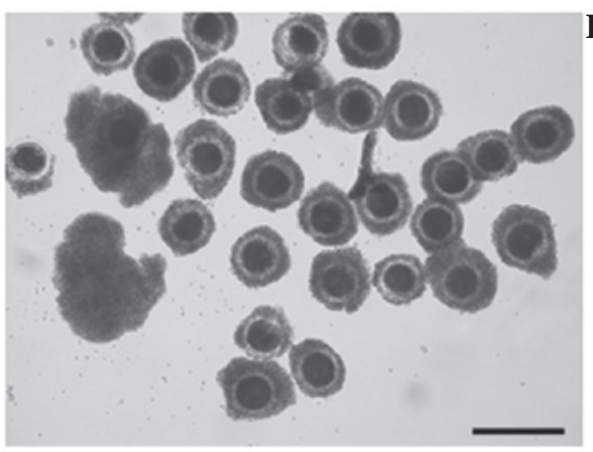

D

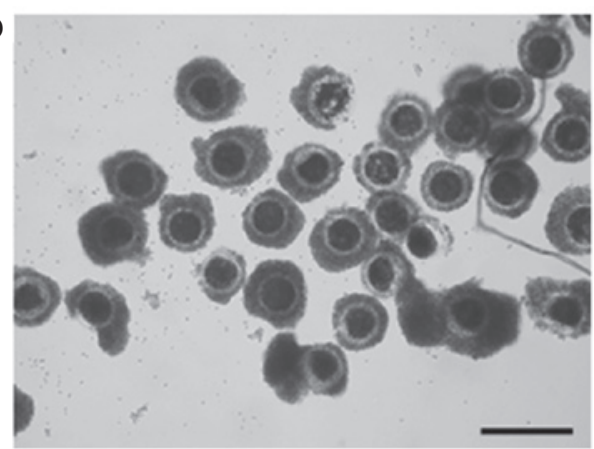

Figure 6. Effect of zinc-deficient time during IVM on cumulus cell expansion at $42 \mathrm{~h}$ after IVM. (A) Control (no treatment), (B) $7 \mathrm{~h}$ TPEN treatment, (C) $15 \mathrm{~h}$ TPEN treatment and (D) $22 \mathrm{~h}$ TPEN treatment (magnification, x50; scale bar, $250 \mu \mathrm{m}$ ). The control group shows abundant cumulus cell expansion. Slight cumulus cell expansion was observed in B. However, cumulus cell expansion was inhibited in C and D. IVM, in vitro maturation; TPEN, zinc chelator N,N,N',N'-tetrakis-(2-pyridylmethyl)-ethylendiamine. 


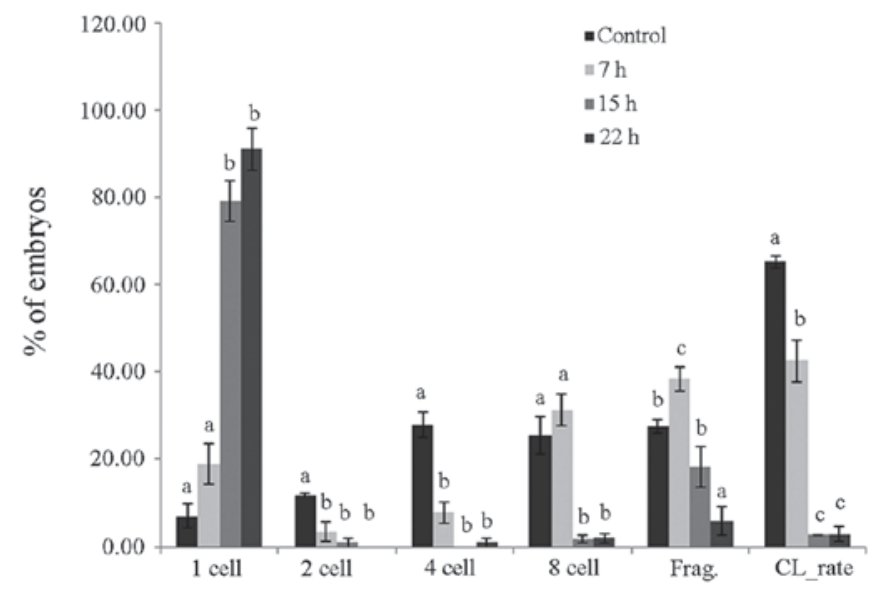

Figure 7. Effect of zinc-deficiency periods during in vitro maturation on cleavage patterns on day 2 . Values are expressed as the mean \pm standard error of the mean $(n=3) .{ }^{a-c} \mathrm{P}<0.05$ between values with different footnotes within a column. Frag, fragmented embryos, which contain unequally-sized blastomeres and multiple cellular fragments; $C L \_$rate, cleave rates, ratio of 2- to 8-cell embryos.

\section{Discussion}

The IVM environment has a prominent effect on oocyte maturation and early embryonic development. Various factors are known to affect oocyte and embryonic development. However, the contribution of zinc to porcine oocyte maturation has yet to be determined. In the present study, the involvement of zinc in porcine oocyte maturation was investigated by inducing zinc deficiency during porcine IVM.

A decrease in the zinc concentration of oocytes was induced by TPEN treatment. TPEN is a lipid-soluble zinc metal chelator that decreases the intracellular levels of zinc (32). Although TPEN has a strong affinity for transition metals, including iron, copper (33) and zinc, while the content of other metals is unchanged relative to that of control cells, TPEN treatment only significantly reduces the zinc content compared with that in the control group (34). TPEN is usually used as a zinc-specific chelator in in vitro studies $(35,36)$. The concentration of TPEN was set at $10 \mu \mathrm{M}$ in accordance with the protocols of previous studies. According to Kim et al (34), concentrations $<10 \mu \mathrm{M}$ did not have any effect on meiotic maturation, whereas concentrations $\geq 20 \mu \mathrm{M}$ had toxic effects on mice oocytes.

In the present study, a decrease in cumulus cell expansion was observed as the first effect of TPEN treatment. Cumulus cell expansion occurred normally in the control and TPEN+zinc-treated groups but not in the TPEN-treated group. TPEN-induced zinc deficiency was previously shown to markedly increase apoptosis induced by cytokines, lipids and oxidative stress in somatic cells (37-39). Apoptosis caused by zinc deficiency may also inhibit cumulus cell expansion. Cumulus cells have an important role in oocyte maturation. Cumulus cells surround each individual oocyte and are functionally associated to the nuclear or cytoplasmic maturation of oocytes (40). Cumulus cells control nuclear maturation by maintaining a meiotic block at the germinal vesicle stage (41) and trigger the resumption of meiosis by secreting a meiosis-inducing substance (8). Cumulus cells are required for cytoplasmic maturation and developmental competence during IVM as they synthesize and transport GSH to oocytes (42). Thus, poor expansion of cumulus cells has a negative impact on oocyte maturation.

In the present study, nuclear maturation was also affected by TPEN-induced zinc deficiency. MI oocytes increased in number, while MII oocytes decreased in number only in the TPEN-treated group. TPEN treatment causes a meiotic block at telophase I during mouse IVM (34); however, in the present study, the rates of anaphase and telophase did not change in any of the groups, possibly due to differences in the meiotic process or the role of zinc in meiosis in different species. In conventional IVM of porcine oocytes, most incompetent oocytes are arrested at MI (43), and zinc deficiency may be a factor leading to MI arrest. As described above, poor cumulus cell expansion would also have affected nuclear maturation.

Meiotic spindle morphology accurately reflects an oocyte's meiotic status $(44,45)$. Therefore, spindle morphology was investigated by $\alpha$-tubulin immunofluorescence. The control and TPEN+zinc-treated groups developed a metaphase spindle with a polar body, whereas the TPEN-treated group only developed a metaphase spindle. According to Ueno et al (46), spindle morphology indicates oocyte quality. However, in the present study, the shape and size of the spindles were similar in all groups. The spindle length was $\sim 10 \mu \mathrm{m}$, the spindle was round, and no significant differences were observed between the experimental groups. Thus, zinc deficiency did not directly affect the meiotic spindle.

Microfilaments are cytoskeletal components with an important role during cell division (47). In the present study, microfilament abnormalities were observed in the TPEN-treated group. A previous study showed that the microfilament area exists at the cortex during metaphase in porcine oocytes (48). However, microfilaments occurred randomly in the cytoplasm and cortex of TPEN-treated oocytes. Abnormal microfilament distribution would affect meiotic maturation. Longo and Chen (49) reported on the role of microfilaments during meiosis in mouse oocytes. Their study showed that the meiotic spindle with chromatin failed to move to the oocyte cortex, and extrusion of the polar body was inhibited by treatment with the microfilament-disrupting agent cytochalasin B. This result provided an explanation for the meiotic block and failure of polar body extrusion in TPEN-treated oocytes. It also suggested that zinc is involved in microfilament distribution during porcine oocyte maturation.

In the TPEN-treated group, the decreased GSH and increased ROS levels indicated poor cytoplasmic maturity. The GSH concentration increases during IVM, reaching its highest level at MII $(50,51)$. Decreased GSH in the TPEN-treated oocytes can be explained by reduced cumulus cell expansion or decreased synthesis due to improper cytoplasmic maturation. The increased ROS levels in the TPEN-treated oocytes implied a lack of anti-oxidant activity of GSH and zinc. The main functions of GSH in oocytes include anti-oxidant activity and protection against the harmful effects of ROS (52). Although the underlying mechanisms have yet to be elucidated, zinc is also involved in protecting oocytes from oxidative stress (53). Zinc acts as an anti-oxidant at multiple cell levels (54) and can induce the synthesis of metallothionein, a protein that chelates redox-active metals and scavenges hydroxyl radicals 
via its cysteine groups (55). Zinc is an important constituent of $\mathrm{Cu} / \mathrm{Zn}$ superoxide dismutase (56), which scavenges free oxygen radicals. Numerous studies have reported that a zinc deficiency induces oxidative stress in in vitro-cultured cells (57-59).

Improper cytoplasmic maturation is a major problem in IVM of porcine oocytes. The low developmental potential of porcine oocytes during IVM is the result of improper cytoplasmic maturation. In the present study, improper cytoplasmic maturation due to zinc deficiency led to decreased embryonic development. Thus, the role of zinc in the maturation process is important.

The duration of zinc deficiency also affected porcine oocyte maturation. TPEN treatment fir $>7 \mathrm{~h}$ inhibited cumulus cell expansion and meiotic maturation. Furthermore, oocytes did not recover with zinc supplementation after $>15 \mathrm{~h}$ of TPEN treatment. In previous studies on mouse oocytes, normal oocyte meiotic maturation occurred with TPEN treatment for $<7 \mathrm{~h}$, whereas meiotic maturation was inhibited by TPEN exposure for $>12 \mathrm{~h}$. Although $9 \mathrm{~h}$-exposed oocytes reached MII, they had a large spindle and polar body (34). These results were not observed in porcine oocytes. The effect of zinc on microfilaments may therefore be different between species. In mice, meiotically blocked oocytes due to TPEN treatment displayed a normal microfilament distribution and cleavage, whereas an abnormal microfilament distribution was present and no cleavage occurred in TPEN-treated pig oocytes.

In conclusion, the results of the present study showed that nuclear and cytoplasmic maturation were decreased in zinc-deficient porcine oocytes. Furthermore, zinc deficiency decreased subsequent embryonic development. In addition, zinc deficiency for $>1$ h caused irreversible damage to oocytes. These results indicated that zinc regulates the meiotic process and has important roles in oocyte maturation. Additional studies are required to identify the mechanism of action of zinc during oocyte maturation.

\section{Acknowledgements}

This work was supported, in part, by a grant from the Next-Generation Bio Green 21 Program (no. PJ00956901), Rural Development Administration, and the National Research Foundation of Korea Grant funded by the Korean Government (nos. NRF-2012R1A1A4A01004885 and NRF-2013R1A2A2A04008751), Republic of Korea.

\section{References}

1. Sirard MA, Richard F, Blondin P and Robert C: Contribution of the oocyte to embryo quality. Theriogenology 65: 126-136, 2006

2. Mattioli M, Bacci ML, Galeati G and Seren E: Developmental competence of pig oocytes matured and fertilized in vitro. Theriogenology 31: 1201-1207, 1989.

3. Singh B, Barbe GJ and Armstrong DT: Factors influencing resumption of meiotic maturation and cumulus expansion of porcine oocyte-cumulus cell complexes in vitro. Mol Reprod Dev 36: 113-119, 1993.

4. Funahashi H, Cantley $\mathrm{T}$ and Day BN: Different hormonal requirements of pig oocyte-cumulus complexes during maturation in vitro. J Reprod Fertil 101: 159-165, 1994.

5. Funahashi H and Day BN: Effects of the duration of exposure to hormone supplements on cytoplasmic maturation of pig oocytes in vitro. J Reprod Fertil 98: 179-185, 1993.

6. Illera MJ, Lorenzo PL, Illera JC and Petters RM: Developmental competence of immature pig oocytes under the influence of EGF, IGF-I, follicular fluid and gonadotropins during IVM-IVF processes. Int J Dev Biol 42: 1169-1172, 1998.
7. Bing YZ, Naga T and Rodriguez-Martinez H: Effects of cysteamine, fsh and estradiol-17beta on in vitro maturation of porcine oocytes. Theriogenology 55: 867-876, 2001.

8. Xia GL, Kikuchi K, Noguchi J and Izaike Y: Short time priming of pig cumulus-oocyte complexes with FSH and forskolin in the presence of hypoxanthine stimulates cumulus cells to secrete a meiosis-activating substance. Theriogenology 53: 1807-1815, 2000.

9. Tatemoto H, Sakurai N and Muto N: Protection of porcine oocytes against apoptotic cell death caused by oxidative stress during in vitro maturation: Role of cumulus cells. Biol Reprod 63: 805-810, 2000.

10. Cetica PD, Pintos LN, Dalvit GC and Beconi MT: Antioxidant enzyme activity and oxidative stress in bovine oocyte in vitro maturation. IUBMB Life 51: 57-64, 2001.

11. Nasr-Esfahani MH, Aitken JR and Johnson MH: Hydrogen peroxide levels in mouse oocytes and early cleavage stage embryos developed in vitro or in vivo. Development 109: 501-507, 1990.

12. Luberda $\mathrm{Z}$ : The role of glutathione in mammalian gametes. Reprod Biol 5: 5-17, 2005.

13. Yoshida M, Ishigaki K, Nagai T, Chikyu M and Pursel VG: Glutathione concentration during maturation and after fertilization in pig oocytes: Relevance to the ability of oocytes to form male pronucleus. Biol Reprod 49: 89-94, 1993.

14. Jeong BS and Yang X: Cysteine, glutathione and Percoll treatments improve porcine oocyte maturation and fertilization in vitro. Mol Reprod Dev 59: 330-335, 2001.

15. Biswas D, Jeon Y, Kim GH, Jeung EB and Hyun SH: Effect of vascular endothelia growth factor on in vitro porcine oocyte maturation and subsequent developmental competence after parthenogenesis. J Anim Vet Adv 9: 2924-2931, 2010.

16. Kwak SS, Jeung SH, Biswas D, Jeon YB and Hyun SH: Effects of porcine granulocyte-macrophage colony-stimulating factor on porcine in vitro-fertilized embryos. Theriogenology 77 : 1186-1197, 2012.

17. Walker SC, Shin T, Zaubrecher GM, Romano JE, Johnson GA, Bazer FW and Piedrahita JA: A highly efficient method for porcine cloning by nuclear transfer using in vitro-matured oocytes. Cloning Stem Cells 4: 105-112, 2002.

18. Nielsen FH: Ultratrace minerals mythical elixirs or nutrients of concern?. Bol Asoc Med P R 83: 131-133, 1991.

19. Hostetler CE, Kincaid RL and Mirando MA: The role of essential trace elements in embryonic and fetal development in livestock. Vet J 166: 125-139, 2003.

20. Vallee BL and Falchuk KH: The biochemical basis of zinc physiology. Physiol Rev 73: 79-118, 1993.

21. Favier AE: The role of zinc in reproduction. Hormonal mechanisms. Biol Trace Elem Res 32: 363-382, 1992.

22. Bedwal RS and Bahuguna A: Zinc, copper and selenium in reproduction. Experientia 50: 626-640, 1994.

23. Hostetler CE, Cronrath JD, Becker WC and Mirando MA: Dietary supplementation of proteinated trace minerals (OPTiMIN) in sows and replacement gilts increases mineral concentrations in reproductive tissues. Abstracts 14th International Congress Animal Reproduction 1: 272, 2000.

24. Wauben IP, Xing HC and Wainwright PE: Neonatal dietary zinc deficiency in artificially reared rat pups retards behavioral development and interacts with essential fatty acid deficiency to alter liver and brain fatty acid composition. J Nutr 129: 1773-1781, 1999.

25. Sakuma S, Fujimoto Y, Miyata Y, Ohno M, Nishida H and Fujita T: Effects of Fe (2+), Zn (2+), Cu (2+) and Se (4+) on the synthesis and catabolism of prostaglandins in rabbit gastric antral mucosa. Prostaglandins Leukot Essent Fatty Acids 54: 193-197, 1996.

26. Sakuma S, Fujimoto Y, Kitao A, Sakamoto H, Nishida H and Fujita T: Simultaneous measurement of prostaglandin and arachidonoyl CoA formed from arachidonic acid in rabbit kidney medulla microsomes: The roles of $\mathrm{Zn} 2+$ and $\mathrm{Cu} 2+$ as modulators of formation of the two products. Prostaglandins Leukot Essent Fatty Acids 61: 105-112, 1999.

27. Chanmugam P, Wheeler C and Hwang DH: The effect of zinc deficiency on prostaglandin synthesis in rat testes. J Nutr 114: 2066-2072, 1984.

28. de Haan JB, Tymms MJ, Cristiano F and Kola I: Expression of copper/zinc superoxide dismutase and glutathione peroxidase in organs of developing mouse embryos, fetuses and neonates. Pediatr Res 35: 188-196, 1994.

29. Chesters JK: Trace element-gene interactions with particular reference to zinc. Proc Nutr Soc 50: 123-129, 1991. 
30. Jeon Y, Yoon JD, Cai L, Hwang SU, Kim E, Zheng Z, Lee E, Kim DY and Hyun SH: Supplementation of zinc on oocyte in vitro maturation improves preimplatation embryonic development in pigs. Theriogenology 82: 866-874, 2014.

31. Jeon Y, Kwak SS, Cheong SA, Seong YH and Hyun SH: Effect of trans-epsilon-viniferin on in vitro porcine oocyte maturation and subsequent developmental competence in preimplantation embryos. J Vet Med Sci 75: 1277-1286, 2013.

32. Treves S, Trentini PL, Ascanelli M, Bucci G and Di Virgilio F: Apoptosis is dependent on intracellular zinc and independent of intracellular calcium in lymphocytes. Exp Cell Res 211: 339-343, 1994.

33. Smith RM and Martell AE: NIST critically selected stability constants of metal complexes database. National Institute of Standards and Technology, 2004. http://www.nist.gov/srd/ upload/46 8.htm. Accessed June 22nd, 2015.

34. Kim AM, Vogt S, O'Halloran TV and Woodruff TK: Zinc availability regulates exit from meiosis in maturing mammalian oocytes. Nat Chem Biol 6: 674-681, 2010.

35. Hyun HJ, Sohn JH, Ha DW, Ahn YH, Koh JY and Yoon YH: Depletion of intracellular zinc and copper with TPEN results in apoptosis of cultured human retinal pigment epithelial cells Invest Ophthalmol Vis Sci 42: 460-465, 2001.

36. Nakatani T, Tawaramoto M, Opare Kennedy D, Kojima A and Matsui-Yuasa I: Apoptosis induced by chelation of intracellular zinc is associated with depletion of cellular reduced glutathione level in rat hepatocytes. Chem Biol Interact 125: 151-163, 2000.

37. Pang W, Leng X, Lu H, Yang H, Song N, Tan L, Jiang Y and Guo C: Depletion of intracellular zinc induces apoptosis of cultured hippocampal neurons through suppression of ERK signaling pathway and activation of caspase-3. Neurosci Lett 552: 140-145, 2013.

38. Mendivil-Perez M, Velez-Pardo C and Jimenez-Del-Rio M: TPEN induces apoptosis independently of zinc chelator activity in a model of acute lymphoblastic leukemia and ex vivo acute leukemia cells through oxidative stress and mitochondria caspase-3- and AIF-dependent pathways. Oxid Med Cell Longev 2012: 313275, 2012.

39. Meerarani P, Ramadass P, Toborek M, Bauer HC, Bauer H and Hennig B: Zinc protects against apoptosis of endothelial cells induced by linoleic acid and tumor necrosis factor alpha. Am J Clin Nutr 71: 81-87, 2000.

40. Abeydeera LR: In vitro production of embryos in swine Theriogenology 57: 256-273, 2002.

41. Tanghe S, Van Soom A, Nauwynck H, Coryn M and de Kruif A: Minireview: Functions of the cumulus oophorus during oocyte maturation, ovulation and fertilization. Mol Reprod Dev 61: 414-424, 2002

42. Maedomari N, Kikuchi K, Ozawa M, Noguchi J, Kaneko H, Ohnuma K, Nakai M, Shino M, Nagai T and Kashiwazaki N: Cytoplasmic glutathione regulated by cumulus cells during porcine oocyte maturation affects fertilization and embryonic development in vitro. Theriogenology 67: 983-993, 2007.

43. Kikuchi K, Somfai T, Nakai M and Nagai T: Appearance, fate and utilization of abnormal porcine embryos produced by in vitro maturation and fertilization. Soc Reprod Fertil Suppl 66: 135-147, 2009.
44. Buendia B, Clarke PR, Félix MA, Karsenti E, Leiss D and Verde F: Regulation of protein kinases associated with cyclin $\mathrm{A}$ and cyclin B and their effect on microtubule dynamics and nucleation in Xenopus egg extracts. Cold Spring Harb Symp Quant Biol 56: 523-532, 1991.

45. Albertini DF: Cytoplasmic reorganization during the resumption of meiosis in cultured preovulatory rat oocytes. Dev Biol 120: 121-131, 1987.

46. Ueno S, Kurome M, Ueda H, Tomii R, Hiruma K and Nagashima H: Effects of maturation conditions on spindle morphology in porcine MII oocytes. J Reprod Dev 51: 405-410, 2005.

47. Roberts K, Raff M, Alberts B, Walter P, Lewis J and Johnson A: Molecular Biology of the Cell. 5th edition. Routledge, London, 2002.

48. Kim NH, Funahashi H, Prather RS, Schatten G and Day BN: Microtubule and microfilament dynamics in porcine oocytes during meiotic maturation. Mol Reprod Dev 43: 248-255, 1996.

49. Longo FJ and Chen DY: Development of cortical polarity in mouse eggs: involvement of the meiotic apparatus. Dev Biol 107: 382-394, 1985.

50. Funahashi H, Cantley TC, Stumpf TT, Terlouw SL and Day BN: Use of low-salt culture medium for in vitro maturation of porcine oocytes is associated with elevated oocyte glutathione levels and enhanced male pronuclear formation after in vitro fertilization. Biol Reprod 51: 633-639, 1994.

51. Zuelke KA, Jeffay SC, Zucker RM and Perreault SD: Glutathione (GSH) concentrations vary with the cell cycle in maturing hamster oocytes, zygotes and pre-implantation stage embryos. Mol Reprod Dev 64: 106-112, 2003.

52. Brad AM, Bormann CL, Swain JE, Durkin RE, Johnson AE, Clifford AL and Krisher RL: Glutathione and adenosine triphosphate content of in vivo and in vitro matured porcine oocytes. Mol Reprod Dev 64: 492-498, 2003.

53. Powell SR: The antioxidant properties of zinc. J Nutr 130 (5S Suppl): 1447S-1454S, 2000.

54. Bray TM and Bettger WJ: The physiological role of zinc as an antioxidant. Free Radic Biol Med 8: 281-291, 1990.

55. Sato $M$ and Bremner I: Oxygen free radicals and metallothionein. Free Radic Biol Med 14: 325-337, 1993.

56. Olin KL, Golub MS, Gershwin ME, Hendrickx AG, Lonnerdal B and Keen CL: Extracellular superoxide dismutase activity is affected by dietary zinc intake in nonhuman primate and rodent models. Am J Clin Nutr 61: 1263-1267, 1995.

57. Ho E and Ames BN: Low intracellular zinc induces oxidative DNA damage, disrupts p53, NFkappa B, and AP1 DNA binding, and affects DNA repair in a rat glioma cell line. Proc Natl Acad Sci USA 99: 16770-16775, 2002.

58. Oteiza PI, Clegg MS, Zago MP and Keen CL: Zinc deficiency induces oxidative stress and AP-1 activation in 3 T3 cells. Free Radic Biol Med 28: 1091-1099, 2000.

59. Song Y, Leonard SW, Traber MG and Ho E: Zinc deficiency affects DNA damage, oxidative stress, antioxidant defenses, and DNA repair in rats. J Nutr 139: 1626-1631, 2009. 